\title{
DETERMINATION OF POSITIVE EMOTIONS IN KURDISH COWS USING PERIPHERAL TEMPERATURES
}

\author{
NAWROZ AKRAM KAKARASH ${ }^{1}$; BASIM ABDULWAHID ALI ${ }^{2}$; \\ HARDI FATTAH MARIF ${ }^{2}$; ZANA MUSTAFA RASHID ${ }^{3}$ \\ AND DANA OMER ISMAEEL ${ }^{4}$ \\ ${ }^{1}$ Department of Anatomy and Histopathology, College of Veterinary Medicine, University of \\ Sulaimani, Sulaymaniyah, Kurdistan Region- Iraq. \\ ${ }^{2}$ Department of Clinic and Internal Medicine, College of Veterinary Medicine, University of \\ Sulaimani, Sulaymaniyah, Kurdistan Region-Iraq. \\ ${ }^{3}$ Department of Microbiology, College of Veterinary Medicine, University of Sulaimani, \\ Sulaymaniyah, Kurdistan Region-Iraq. \\ ${ }^{4}$ Department of Surgery and Theriogenology, College of Veterinary Medicine, University of \\ Sulaimani, Sulaymaniyah, Kurdistan Region, Northern Iraq.
}

Received: 22 September 2021; Accepted: 28 October 2021

\begin{abstract}
Animal welfare science has been focused on how animal express their emotion. The emotion can be either positive or negative. The connections between positive emotion and peripheral temperatures are relatively neglected. Therefore, the current study was designed to measure nasal and ear pinna temperatures as a method to determine positive emotional state in Kurdish cow produced by gentle stroking of the animal body. Twelve Kurdish cows, aged 3-7 years, were used in this study. The cows were stroked in preferred regions (shoulder, neck and withers) to induce positive emotional state. The stroking manner was similar to allogrooming. The temperature data were collected from both nose and ear pinna of the animals in three different stages including pre-stroking, stroking and post-stroking. Each stage lasted five minutes. Focal animal sampling method was used to collect the data. Results showed that the three stages of nasal temperature were significantly different $(\mathrm{P}<0.001)$, and significant difference was also seen between the stages of ear pinna temperatures $(\mathrm{P}<0.05)$. In addition, strong correlation coefficient $(\mathrm{r}=0.91)$ was found between nasal and ear pinna temperatures. Both nasal and ear pinna temperatures decreased over time. It was concluded that peripheral temperatures in Kurdish cows is a good welfare indicator and provide a useful measure for positive emotional state.
\end{abstract}

Keywords: Kurdish cow, Stroking, Infrared thermometer gun, Eye and nasal temperatures.

\section{INTRODUCTION}

Animals similar to humans are emotional creatures, they can feel and have

Corresponding author: Hardi Fattah Marif

E-mail address: hardi.marif@univsul.edu.iq

Present address: Department of Clinic and Internal

Medicine, College of Veterinary Medicine, University of Sulaimani, Sulaymaniyah, Kurdistan Region-Iraq emotions. Therefore, animals have a right to live in a good welfare state. Good animal welfare is not only obtained by providing a suitable environment, but also requires the consideration of their emotional states (Proctor and Carder, 2016). In humans, welfare is evaluated via oral communication or written report on their emotions (Herr et al., 2006). While, in animals, welfare assessment needs some indicators to be 
understood (Guatteo et al., 2012, Boissy and Lee, 2014). The indicators are mostly associated with physiology and behaviour (Watts, 2014). Based on physiological indicator, in non-human animals, measuring surface temperatures such as eyes, nose, ears are commonly used for estimating of the emotional state (Proctor \& Carder, 2015; Hussein, 2019).

For instance, in mammals like cattle and sheep, psychological and physical stresses lead to increase in core body temperature for a short period of time. This increment is known as emotional fever and is a convenient indicator for estimating animal welfare (Macaulay et al., 1995; Sellier et al., 2014, Proctor \& Carder, 2015). The core body temperature measurement needs handling and manipulating of the animals, which affects the animals' emotional state (Stewart et al., 2008). Therefore, the scientists used non-invasive measures such as infrared thermometer or thermography and ear postures as an alternative way to detect the animals' emotional state (Proctor \& Carder, 2016; Hussein and Hidayet, 2019).

Emotional stimuli due to sympathetic nervous system lead to vasoconstrictions of peripheral areas resulting in diverting blood from these areas toward the vital organs which causes change in temperatures (Nakayama et al., 2005). Corticotropin releasing factor (CRF) secreted by hypophysiotropic neuron which is the principle regulator of hypothalamic pituitary axis (HPA). During the response to emotions, CRF accesses the anterior pituitary gland after released into the hypophysial portal system. Then, adrenocorticotropic hormone (ACTH) releases into the circulatory system as result of binding CRF to its receptor on pituitary corticotropes. ACTH stimulates the synthesis of glucocorticoid. Glucocorticoids work as downstream effectors of HPA axis and distribute ubiquitously in the intracellular receptors to regulate physiological changes (Smith and Vale, 2006). Activation of HPA also causes an increase in the concentrations of catecholamine and glucocorticoid, together with reduced blood flow in the peripheral area, resulting in heat loss which can be detected by drop in peripheral temperature such as nasal temperature. (Jansen et al., 1995). In sheep and primates (rhesus macaques), ear and nasal temperatures were used to determine negative emotion respectively (Beausoleil et al., 2004; Kuraoka and Nakamura, 2011).

Peripherals temperature widely used to determine negative emotions in different animals (Proctor \& Carder, 2015). According to Boivin et al. (2003) changes in peripheral temperature were seen during positive stroking in sheep, goat and pig. The stroking of animals' body for example, neck, shoulder, withers and back are commonly used during interactions between stockman and animals (Schmied et al., 2008). Studies showed that gentle stroking improved handling (Boivin et al., 1992), decreased fear from humans (Rushen et al., 1999), reduced distress (Tallet et al., 2005) and improved the quality of meat (Lensink et al., 2001).

In cattle, eyes temperature was used to detect negative states such as fear and pain (Stewart et al., 2008), and nasal temperature determined both positive and negative emotions (Proctor \& Carder, 2015; Proctor $\&$ Carder, 2016). While, no study has been conducted on gentle stroking of cow's body to determine positive emotional states, particularly in Kurdish cows. Therefore, the present research was carried out to use both nasal and ear pinna temperatures as a method to determine positive emotional state in Kurdish cows.

\section{MATERIALS AND METHODS}

\section{Study site and subjects}

The study was conducted in Tanjaro Village. The Village locates in the South-West of 
Sulaimani, Kurdistan Region of Iraq. The study was undertaken on April and May 2020. Twelve Kurdish cows aged 3-7 years were used in the study. Kurdish farmers in the Villages generally like moving out their animals for grazing during the daylight especially in spring. Therefore, the animals were freely moved out for grazing and drinking, while during the study, the cows were kept at their places, food and water were also provided at their housing.

\section{Data collection process}

Data were collected using focal animal sampling method. Infrared thermometer gun (Benetech, Inc, USA) was used to take temperature data from both nose and ear pinna of the animals. The gun had red laser point to detect the precise area on the animal's body during temperature measurement. Emissivity and temperature of environment may affect the temperature values taken by the gun. Therefore, thermometer was used to adjust the environmental temperature and the surface emissivity of cows' body was estimated by 0.98 above the temperature of the infrared thermometer gun (Hoffmann et al., 2013). Surface emissivity is the ability of cow to emit and absorb the infrared radiation.

According to Stewart et al. (2007) and Proctor and Carder (2015), the temperature was measured at distance 0.5 to 1 meter on the right side of the animals' head with $0-15^{\circ}$ angle. The temperature was taken from the outer part of nose and pinna of the ear. These areas were cleaned using disposable towel from dust and other substances an hour before recording the data, because surface emissivity changes by dirt and other materials (Mc Cafferty, 2007; Sellier et al., 2014). The cows were stroked on the neck, shoulder and withers for five minutes. The temperature data were collected during 15 minutes at three different stages including prestroking (before stroking), stroking and poststroking (after stroking). Each stage took five minutes. In pre-stroking stage, the temperature data at the 00:30 (minutes: seconds) and 04:30 stopwatch points, during stroking at 05:00 and 09:30 stopwatch points, then during poststroking at 10:30 and 14:30 stopwatch points were taken (i.e. twice at each stage). A total of 1440 temperature readings were collected, 120 readings from each cow, 60 readings from nasal and 60 readings from ear pinna.

\section{Data analysis}

Microsoft Excel spreadsheet was used to save and prepare the data for analysis. Genstat Software Program (17th edition, VSN International Ltd, UK) was used to analyse the data. The data were parametric according to Shapiro-Wilk normality test. One-Way Analysis of Variance (ANOVA) repeated measures used to find the differences in the mean of the three stages of each ear pinna and nasal temperatures separately. Fisher's Unprotected Least Significant Difference (LSD) test was used for post hoc comparisons. Person's correlation coefficient was used to find the correlation between nasal and ear pinna temperature.

\section{RESULTS}

\section{Effect of stages on the temperatures}

The results of nasal and ear pinna temperatures for the three stages of stroking are presented in Table 1. ANOVA analysis demonstrated significant difference between the mean of nasal temperature's stages as well as between the mean of ear pinna temperature's stages. The Fisher's Unprotected LSD test illustrated that the mean of nasal temperature in pre-stroking stage was significantly higher than those taken during stroking $(P<0.001)$ and post-stroking $(P<0.001)$. Furthermore, the nasal temperatures of stroking stage and post-stroking stage were also significantly difference $(P<0.001)$. Regarding ear pinna temperature, Fisher's Unprotected LSD also displayed significant difference between pre-stroking and stroking stages $(P<0.05)$, pre-stroking and post-stroking stages $(P<0.05)$ as well as stroking and post-stroking stages $(P<0.05)$. 
Table 1: Mean values of Nasal and ear pinna temperatures in Kurdish cow of pre, during and post-stroking stages

\begin{tabular}{lccc}
\hline \multicolumn{1}{c}{ Temperature sites } & \multicolumn{3}{c}{ Stages } \\
\hline & Pre-stroking & Stroking & Post-stroking \\
Nasal & $27.7 \pm 0.03^{\mathrm{a}}$ & $26.2 \pm 0.02^{\mathrm{b}}$ & $25.4 \pm 0.06^{\mathrm{c}}$ \\
Ear pinna & $35.8 \pm 0.03^{\mathrm{a}}$ & $35.1 \pm 0.04^{\mathrm{b}}$ & $34.2 \pm 0.1^{\mathrm{c}}$ \\
\hline
\end{tabular}

Note: Values refers means of temperature $(n=60)$ and standard error $(\mathrm{SE}) . \mathrm{a}, \mathrm{b}$, and c letters refer statistically difference $(\mathrm{P} \leq 0.05)$ within the rows, in Fisher's Unprotected LSD test-One-Way ANOVA. Use decimal numbering for headings and subheadings.

\section{Correlation of the temperatures}

opwatch points of the three stroking stages was illustrated in figure 1. Pearson's correlation coefficient test found that ear pinna temperature strongly correlated with
The correlation between ear pinna temperature and nasal temperature for all st nasal temperature for all stopwatch points $(\mathrm{r}=0.91)$.

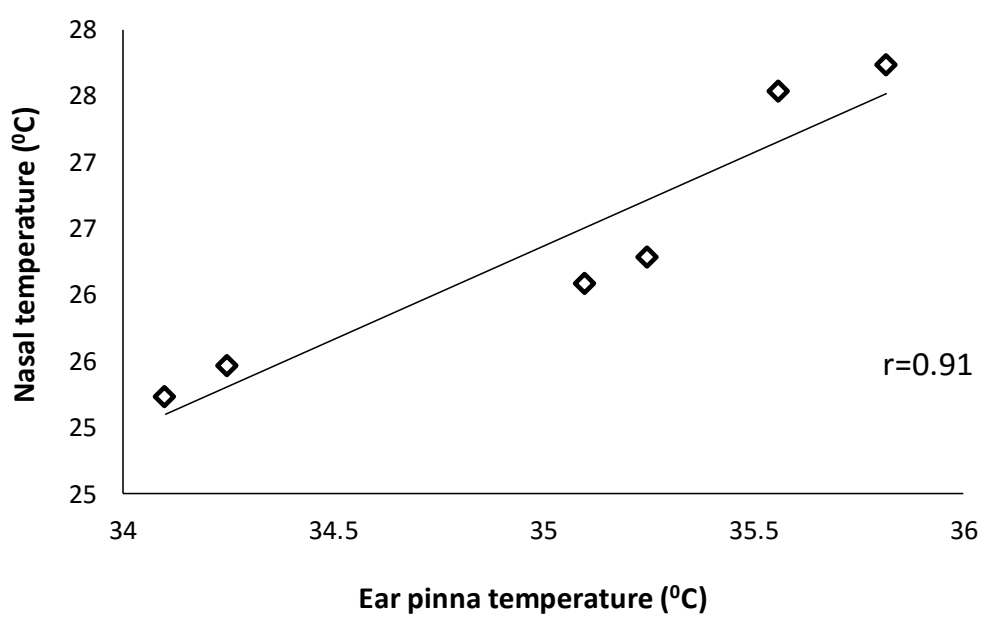

Figure 1: Correlation between mean of ear pinna temperature and nasal temperature in three stages of stroking.

\section{Temperatures during stopwatch points} The means of nasal and ear pinna temperature for all stopwatch points in the three stages of stroking were displayed in figure 2. In general, both nasal and ear pinna temperatures were higher before stroking then gradually decreased during stroking and after stroking at each stopwatch points. In prestroking stage, stopwatch points of 00:30 and 4:30 showed $0.2{ }^{0} \mathrm{C}$ differences in the means of nasal temperature and $0.3{ }^{0} \mathrm{C}$ differences in the means of ear pinna temperature. In addition, during stroking stage, stopwatch points of 05:00 and 09.30 demonstrated $0.41{ }^{0} \mathrm{C}$ difference in the means of nasal temperature and $0.17{ }^{\circ} \mathrm{C}$ difference in the means of ear pinna temperature. Furthermore, stopwatch points of 10:30 and $14: 30$ in the post-stroking stage showed $0.16{ }^{\circ} \mathrm{C}$ difference in the means of nasal temperature and $0.2{ }^{0} \mathrm{C}$ difference in the means of ear pinna temperature. 


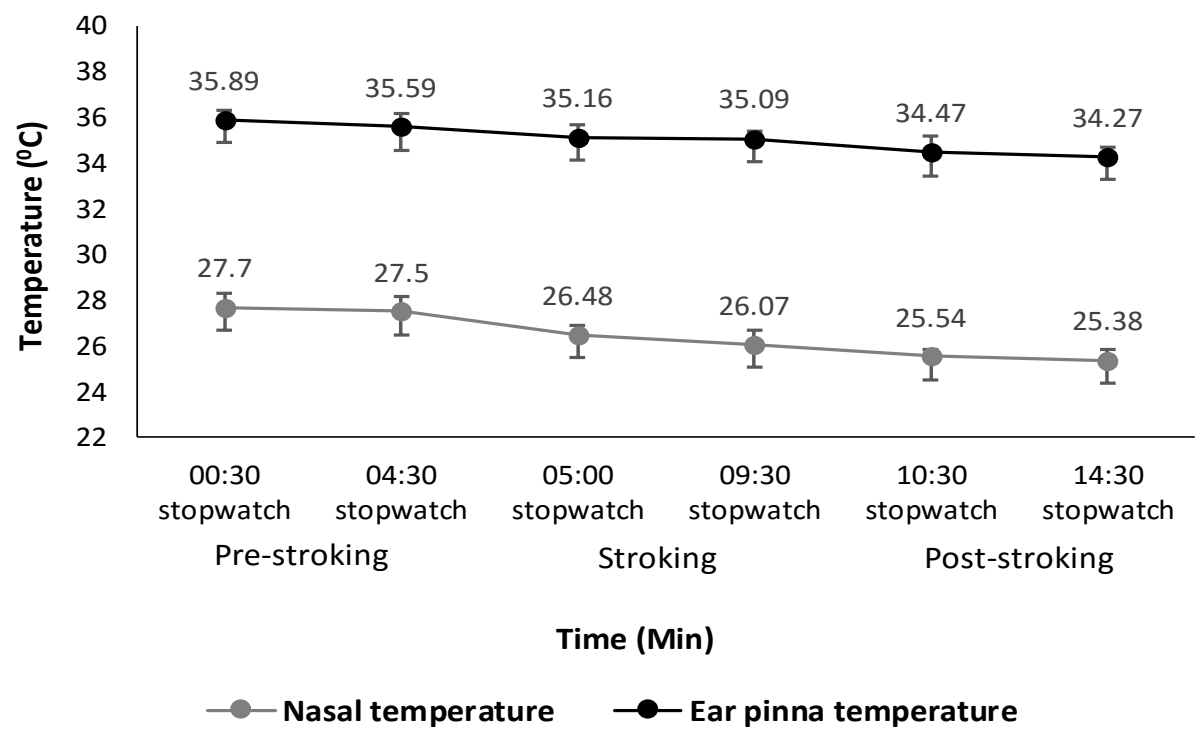

Figure 2: Mean of nasal and ear pinna temperature (0C) of stopwatch points

\section{DISCUSSION}

The current study is attempted to find out whether nasal and ear pin temperatures of Kurdish cows change or not as result of positive emotional state induced by stroking of the animals. It was found that both nasal and ear pinna temperature significantly affected by stroking which determined by drop in the both temperatures. The nasal and ear pinna temperatures were also highly correlated and decreased overtime during stopwatch points. Very little studies have discovered the use of peripheral temperature to indicate cow's positive emotional state, mostly the researches undertaken to find out of negative emotion.

Moe et al. (2012) offered a favored meal for chickens to find out whether the comb temperature changed or not. It was found that the comb temperature dropped significantly after delivering a favoured food. This demonstrated that positive stimuli lead to vasoconstriction of the peripheral area which causes in drop of comb temperature as a result of positive emotional state. In addition, Cabanac and Aizawa, (2000) demonstrated that simple handling of chicken caused decreasing of comb and peripheral temperature. Furthermore, Waiblinger et al. (2004) and Schmied et al. (2010) stated that changes in peripherals temperature and vital sings were mostly correlated and demonstrated that stroking in cow led to decrease in cortisol level and heart rate during veterinary procedure, and the focal cow often felled to sleep during stroking. This indicated that cows felt positive emotion during stroking. By assessing the results of Waiblinger et al. (2004) and Schmied et al. (2010) and combining to the results of Davies and Maconochie (2009) who reported that in human, heart rate has direct relationship with body as well as peripherals temperature, it appears that stroking not only led to decrease in cortisol level and heart rate but also caused decreasing peripherals temperature. From this, it is obvious that decreased in peripherals temperature was an emotional valence rather than arousal. The interaction with toys and tickling in primates caused drop in the tip nose temperature Chotard et al. (2018). Proctor and Carder (2015) induced stroking in preferred regions of cow to determine positive emotional state via nasal temperature; their results found that nasal temperature dropped during stroking. Additionally, Proctor and Carder (2016) offered a favoured concentration to the cows as positive stimuli to detect whether nasal temperature change or not. The nasal temperature was significantly decreased during consumption of the food. It appears 
that above findings are almost similar and support of the current study findings in which positive emotional state was determined by dropping in both nasal and ear pinna temperatures during and after stroking.

On the other hand, changing in peripheral temperature was also used to determine negative emotional state in animals. This view has mostly focused compare to positive emotions. Many studies revealed that stressful and unpleasant stimuli in mammals led to decrease in peripheral temperatures. For instance, in rabbits, temperature in several peripheral areas including skin of ear, bulb of eye and surrounding eye area were decreased after exposed to various negative stimuli and these decreasing were highly correlated (Ludwig et al., 2010). In addition, various stressful handling (Stewart et al., 2005), offering inedible feed (Proctor and Carder, 2016), disbudding (Stewart et al., 2008) and castration with or without anaesthesia (Stewart et al., 2010) led to decrease in nose and eye area temperature significantly.

On the contrary of those research showed various negative stimuli led to decrease peripherals temperature, Panksepp, (2004) demonstrated that most of the negative stimuli, which led to make the animals become anger, raise peripherals temperature, and stated that during anger blood shunted away from the gut toward the muscles to prepare for physical effort. Additionally, rate of heart and respiration increased, as well as blood pressure and body temperature raised up.

In the literature, it is quite seldom that study demonstrated positive emotion led to increase in peripherals temperature in animals particularly in cow. Travain et al. (2016) used positive stimulation by offering palatable food to investigate dog's emotional state. Infrared thermography to measure eye temperature in combination with both heart rate and behavioural measure were used. It was found that heart rate, tail wagging and eye temperature were increased. This finding disagree with the results of the current study in which positive emotion decreased the peripheral temperatures, this may because of types of stimulation, according to Szentirmai et al. (2010) eating food increased body temperature. So far as known both positive and negative emotions mostly led to drop in peripheral areas temperature. Therefore, it would be better for the researchers to measure one or more vital parameters noninvasively with peripheral temperatures to determine emotional state, because most of the vital measures and temperature have direct relationship and strong correlation during change in their values (Davies and Maconochie, 2009).

\section{CONCLUSION}

The current study findings suggest that changes in peripheral temperatures (nasal and ear pinna) offer a useful insight in emotional valence in the cows. more studies using different positive stimuli are required to determine positive emotions and emotional valence in cows based on the changes in the temperature of peripheral areas of the animal's body.

\section{ACKNOWLEDGEMENTS}

The authors are thankful to Mrs. Nazira K. Hama at Tanjaro Village to provide the animals and help through the study.

\section{REFERENCES}

Beausoleil, N.J.; Stafford, K.J. and Mellor, D.J. (2004): Can we use change in core body temperature to evaluate stress in sheep? Proc new zeal. Soc. Anim. Prod., 64: 72- 76.

Boissy, A. and Lee, C. (2014): How assessing relationships between emotions and cognition can improve farm animal welfare. Revue Scientific Technique. (International Office of Epizootics), 33: 103-110. 
Boivin, X.; Le Neindre, P. and Chupin, J.M. (1992): Establishment of cattle-human relationships. Appl. Anim. Behav. Sci., 32(4): 325-335

Boivin, X.; Lensink, J.; Tallet, C. and Vessier, I. (2003): Stockmanship and farm animal welfare. Anim. Welfare, 12: 479-492.

Cabanac, M. and Aizawa, S. (2000): Fever and tachycardia in a bird (Gallus domesticus) after simple handling. Physiol. Behav., 69(4): 541-545.

Chotard, H.; Ioannou, S. and Davila-Ross, $M$. (2018): Infrared thermal imaging: Positive and negative emotions modify the skin temperatures of monkey and ape faces. American journal of primatology, 80(5), e22863.

Davies, P. and Maconochie, I. (2009): The relationship between body temperature, heart rate and respiratory rate in children. Emergency Medicine Journal, 26(9), 641-643.

Guatteo, R.; Levionnois, O.; Fournier, D.; Guemene, D.; Latouche, K.; Leterrier, C.; Mormède, P.; Prunier, A.; Serviere, J.; Terlouw, C. and Le Neindre, P. (2012): Minimising pain in farm animals: the $3 \mathrm{~S}$ approachSuppress, Substitute, Soothe'. Animal, 6(8): 1261-1274.

Herr, K.; Bjoro, K. and Decker, S. (2006): Tools for assessment of pain in nonverbal older adults with dementia: a state-of-thescience review. J. Pain Symptom Manage, 31(2): 170-192.

Hoffmann, G.; Schmidt, M.; Ammon, C.; Rose-Meierhöfer, S.; Burfeind, O.; Heuwieser, W. and Berg, W. (2013): Monitoring the body temperature of cows and calves using video recordings from an infrared thermography camera. Veterinary research communications, 37(2), 9199.

Hussein, N.J. (2018): Using eye and nasal temperatures to measure positive emotions in free-range hamdani sheep. Basrah J. Agric. Sci., 31(2), 24-30.

Hussein, N.J. and Hidayet, H.M. (2019): Changes in Ear Postures of Kid Goats in Response to Ear Tagging. Basrah J. Agric. Sci., 32(1), 25-33.

Jansen, A.S.; Van Nguyen, X.; Karpitskiy, V.; Mettenleiter, T.C. and Loewy, A.D. (1995): Central command neurons of the sympathetic nervous system: basis of the flight-or-flight response. Science, 270(5236): 644-646.

Kuraoka, K. and Nakamura, K. (2011): The use of nasal skin temperature measurements in studying emotion in macaque monkeys. Physiology and behavior, 102(3-4), 347-355.

Lensink, B.J.; Veissier, I. and Florand, L. (2001): The farmers' influence on calves' behaviour, health and production of a veal unit. Anim. Sci., 72(1): 105-116.

Ludwig, N.; Gargano, M.; Luzi, F.; Carenzi, C. and Verga, M. (2010): Applicability of infrared thermography as a noninvasive measurements of stress in rabbit. World Rabbit Sci., 15(4): 199206.

Macaulay, A.S.; Hahn, G.L.; Clark, D.H. and Sisson, D.V. (1995): Comparison of calf housing types and tympanic temperature rhythms in Holstein calves1, 24. J. Dairy Sci., 78 (4): 856862.

Mccafferty, D.J. (2007): The value of infrared thermography for research on mammals: previous applications and future directions. Mammal Review, 37(3), 207-223.

Moe, R.O.; Stubsjфen, S.M.; Bohlin, J.; Flф, A. and Bakken, M. (2012): Peripheral temperature drop in response to anticipation and consumption of a signaled palatable reward in laying hens (Gallus domesticus). Physiol. Behav., 106(4): 527533

Nakayama, K.; Goto, S.; Kuraoka, K. and Nakamura, K. (2005): Decrease in nasal temperature of rhesus monkeys (Macaca mulatta) in negative emotional state. Physiology \& behavior, 84(5), 783-790.

Panksepp, J. (2004): Affective neuroscience: The foundations of human and animal emotions. Oxford university press. 
Proctor, H.S. and Carder, G. (2015): Nasal temperatures in dairy cows are influenced by positive emotional state. Physiology and behavior, 138, 340-344.

Proctor, H. and Carder, G. (2016): Can changes in nasal temperature be used as an indicator of emotional state in cows?. Applied Animal Behaviour Science, 184, 1-6.

Rushen, J.; Taylor, A.A. and de Passillé, A.M. (1999): Domestic animals' fear of humans and its effect on their welfare. Appl. Anim. Behav. Sci., 65(3): 285303.

Schmied, C.; Boivin, X.; Scala, S. and Waiblinger, S. (2010): Effect of previous stroking on reactions to a veterinary procedure: Behaviour and heart rate of dairy cows. Interact. Stud.,11(3): 467-481.

Schmied, C.; Waiblinger, S.; Scharl, T.; Leisch, F. and Boivin, X. (2008): Stroking of different body regions by a human: ffects on behaviour and heart rate of dairy cows. Appl. Anim. Behav. Sci., 109(1): 25-38.

Sellier, N.; Guettier, E. and Staub, C. (2014): A review of methods to measure animal body temperature in precision farming.

Smith, S.M. and Vale, W.W. (2006): The role of the hypothalamic-pituitary axis in neuroendocrine responses to stress. Dialogues in clinical neurosciences, 8(4), 383.

Stewart, M.; Verkerk, G.A.; Stafford, K.J.; Schaefer, A.L. and Webster, J.R. (2010): Noninvasive assessment of autonomic activity for evaluation of pain in calves, using surgical castration as a model. Journal of dairy science, 93(8), 3602-3609.

Stewart, M.; Webster, J.R.; Schaefer, A.L.; Cook, N.J. and Scott, S.L. (2005): Infrared thermography as a non- invasive tool to study animal welfare. Anim. Welfare, 14(4): 319-325.

Stewart, M.; Webster, J.R.; Schaefer, A.L. and Stafford, K.J. (2008): Infrared thermography and heart rate variability for non-invasive assessment of animal welfare. ANZCCART Humane Science News, 21: 1-4.

Stewart, M.; Webster, J.R.; Verkerk, G.A.; Schaefer, A.L.; Colyn, J.J. and Stafford, K.J. (2007): Non-invasive measurement of stress in dairy cows using infrared thermography.Physiol. Behav, 92(3): 520525.

Szentirmai, É.; Kapás, L.; Sun, Y.; Smith, R.G. and Krueger, J.M. (2010): Restricted feeding-induced sleep, activity, and body temperature changes in normal and preproghrelin-deficient mice. American Journal of Physiology-Regulatory, Integrative and Comparative Physiology, 298(2), R467-R477.

Tallet, C.; Veissier, I. and Boivin, X. (2005): Human contact and feeding as rewards for the lamb's affinity to their stockperson. Appl. Anim. Behav. Sci., 94(1): 59-73.

Travain, T.; Colombo, E.S.; Grandi, L.C.; Heinzl, E.; Pelosi, A.; Previde, E.P. and Valsecchi, P. (2016: How good is this food? A study on dogs' emotional responses to a potentially pleasant event using infrared thermography. Physiology \& Behavior, 159, 80-87.

Waiblinger, S.; Menke, C.; Korff, J. and Bucher, A. (2004): Previous handling and gentle interactions affect behaviour and heart rate of dairy cows during a veterinary procedure.Appl. Anim. Behav. Sci., 85: 31-42.

Watts, C. (2014): Tackling Stress in Sheep through the Addition of Natural Feed Supplements. Ph. D. Thesis, Fac. Alfred Univ., New York: 58. 